
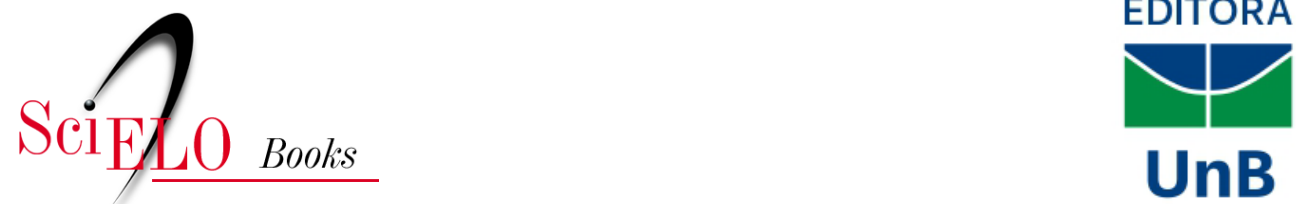

\title{
Capítulo 9 - Entre a inclusão e a exclusão: criatividade em contextos de controvérsias
}

\author{
Paula Pompeu Fiuza Lima
}

\section{SciELO Books / SciELO Livros / SciELO Libros}

LIMA, P. P. F. Entre a inclusão e a exclusão: criatividade em contextos de controvérsias. In: ABERS, R. N., ed. Ativismo institucional: criatividade e luta na burocracia brasileira [online]. Brasília: Editora UnB, 2021, pp. 323-352. ISBN: 978-65-5846-159-3. https://doi.org/10.7476/9786558461593.0010.

\section{(2) ()}

All the contents of this work, except where otherwise noted, is licensed under a $\underline{\text { Creative }}$ Commons Attribution 4.0 International license.

Todo o conteúdo deste trabalho, exceto quando houver ressalva, é publicado sob a licença Creative Commons Atribição 4.0.

Todo el contenido de esta obra, excepto donde se indique lo contrario, está bajo licencia de la licencia Creative Commons Reconocimento 4.0. 


\section{Capítulo 9}

\section{Entre a inclusão e a exclusão: criatividade em contextos de controvérsias}

Paula Pompeu Fiuza Lima

Os programas sociais focalizados têm em seu cerne um conflito fundante: seria melhor afrouxar as regras de participação no programa, correndo o risco de incluir indevidamente alguém fora do perfil mas buscando abarcar todo o público-alvo, ou enrijecer as regras de entrada e permanência no programa arriscando excluir quem está dentro do perfil? Em termos técnicos, é um conflito entre priorizar o erro de exclusão ou de inclusão. Sendo um programa social focalizado, o Programa Bolsa Família (PBF) depara-se com esse conflito diariamente. E é o Cadastro Único para Programas Sociais que possibilita que a entrada e saída das famílias no programa se dê com maior ou menor dificuldade.

O Programa Bolsa Família é um programa de transferência de renda condicionada que visa promover o alívio imediato à pobreza e extrema pobreza e quebrar o ciclo intergeracional de pobreza por meio do provimento de serviços de saúde, educação e assistência social. O Cadastro Único é o registro administrativo que coleta as informações das famílias 
que pleiteiam participar do programa e fornece esses dados aos gestores que verificam se a família tem ou não o perfil para ser beneficiária.

Ganhando cada vez mais visibilidade ao longo dos governos petistas, o Programa Bolsa Família foi alvo de diversas disputas. O conflito entre erro de exclusão e inclusão esteve presente desde o primeiro ano do governo, e causou sua primeira crise de legitimidade quando diversas denúncias apareceram nos noticiários mostrando pessoas fora do perfil recebendo o benefício como, por exemplo, políticos, e até mesmo um gato.

A solução encontrada para blindar politicamente o programa foi entregá-lo, junto ao Cadastro Único, nas mãos de uma equipe de gestores de carreira e dar grande autonomia a esses técnicos para desenvolver soluções para os desafios da política. Aparentemente essa solução foi bem-sucedida, porque muitas das análises sobre a gestão do programa no nível federal reforçam o caráter inovador de vários dos arranjos implementados (OLIVEIRA; LOTTA, 2015).

Considerando as análises que indicam o caráter inovador da gestão do programa, a pergunta que orienta este capítulo é: a experimentação criativa ocorre da mesma forma em todos os contextos? Dito de outra forma: diferentes contextos favorecem diferentes tipos de ação criativa? Quais contextos favorecem quais tipos de ação criativa? Para responder a essas perguntas olharei para três contextos diferentes na implementação do programa Bolsa Família e do Cadastro Único, tentando ressaltar que tipo de inovação foi possível em cada um deles.

O primeiro contexto é o de formulação do programa, quando, nas palavras dos próprios gestores, "se buscava trocar os pneus com o carro andando”. Como indicam Oliveira e Lotta (2015), trata-se da fase heroica do programa, quando tudo estava em construção e a equipe de médio escalão tinha grande autonomia para propor e implementar arranjos experimentais. O segundo contexto foi quando surgiram os primeiros grandes questionamentos dos órgãos de controle sobre a qualidade dos dados do Cadastro Único e a focalização do programa. Mais do que desenvolver arranjos experimentais, a equipe da Secretaria Nacional de Renda de Cidadania (Senarc), gestora do programa, precisa justificar as decisões tomadas com argumentos e normativas. É um momento em que são feitos questionamentos por atores externos, mas o corpo burocrático ainda possui 
grande respaldo interno. Por fim, o terceiro momento é o pós-impedimento da presidenta Dilma Rousseff, quando aqueles que indagam a focalização do programa passam a fazer parte do governo. É um contexto em que os questionamentos internos se somam aos externos.

A maior parte dos dados apresentados foi coletada por meio de entrevistas com os gestores de médio escalão da Senarc e refletem, desse modo, a visão deles. Até o momento foram feitas entrevistas com 12 servidores ou ex-servidores da Senarc. Os ex-gestores foram contatados porque ao longo da pesquisa identificou-se a necessidade de compreender melhor o que motivou algumas das práticas da forma como foram feitas. Duas das entrevistas com servidores foram exploratórias, ou seja, foram baseadas em um roteiro mais livre que possibilitasse identificar questões mais específicas a serem aprofundadas. Elas foram utilizadas no capítulo porque as respostas contribuíam para os objetivos da pesquisa. Todos os entrevistados estão apresentados como mulheres, o que favorece o anonimato dos atores e contribui para uma linguagem inclusiva. É importante ressaltar que sou também servidora da Senarc, o que pode ter enviesado a escolha de alguns dos entrevistados. Tentei minimizar esse efeito buscando incluir na análise atores com poder significativo de decisão, como secretários e ex-secretários, diretores e ex-diretores de departamentos, coordenadores-gerais envolvidos nas ações de averiguação do Cadastro Único e assessores que estão na Senarc há muito tempo e têm memória de muitas das decisões tomadas. Todos os servidores entrevistados possuem ou possuíam no momento em que estavam na Senarc cargos de direção e assessoramento 4, 5 ou 6, i.e., compõem uma elite dirigente do órgão.

O capítulo está dividido em duas seções, sem contar esta introdução e a conclusão. A primeira delas apresenta o marco teórico que norteia as análises. A segunda explora como se deu a experimentação criativa na gestão do Cadastro Único e do Programa Bolsa Família em três diferentes contextos. A partir desse percurso, busco desenvolver como contextos e conflitos podem ser utilizados para compreender a experimentação criativa. 


\section{Contextos conflituosos, soluções criativas}

Compreender a ação criativa significa entender como a agência dos atores se situa em estruturas. Para isso, considera-se que é porque o ator está inserido em estruturas que ele tem recursos que podem modificá-las. Embora as estruturas condicionem a agência, elas só existem porque existe agência (SEWELL JR., 1992).

Nessa perspectiva, a teoria pragmatista contribui para a análise porque compreende que a ação criativa é motivada pela identificação de problemas e pela tentativa de sua resolução. É um processo cotidiano porque os indivíduos sempre se deparam com situações sobre as quais não sabem o que fazer. Nesse processo, os atores utilizam sua inteligência e sua capacidade de construir hipóteses não convencionais para solucionar questões com as quais se deparam. A partir desse processo os atores constroem novos jeitos de agir baseados na reflexão sobre hábitos antigos (JOAS, 1996).

O constante questionamento das próprias premissas permite que o indivíduo aprenda a antecipar problemas, não somente reagindo a situações com as quais se depara (ANSELL, 2013). Isso ocorre porque a capacidade de interpretação das situações ocorre durante a interação social, seja na interação face a face entre indivíduos concretos, seja na interação com categorias abstratas, como o Estado. E nessa interação, o indivíduo se coloca no lugar da pessoa ou coisa com a qual ele interage, tornando-se capaz de imaginar qual a reação desse ator em relação àquele que o interpela (BLUMER, 1969).

Esse processo não se dá sem conflitos, nem sempre o que é considerado problema para alguém é considerado por outra pessoa. Assim, a construção de um problema é permeada por esforços de justificação e acionamento de critérios de justiça. É por meio da comparação da situação vivida com um critério de justiça mais amplo que uma situação é identificada como problema. $\mathrm{O}$ ator, nesse sentido, é um sujeito dotado de capacidade crítica, capaz de argumentar e justificar seus atos de acordo com um senso de justiça ordinário (BOLTANSKI; THÉVENOT, 1999).

Os critérios de justiça, no entanto, nem sempre são os mesmos. Quando há diferentes critérios de justiça, cria-se uma situação de descontentamento ou uma disputa, e uma necessidade de justificação. Para isso 
são utilizados diferentes valores, que podem ser utilizados para justificar ações inseridas em distintos contextos, concordando ou não com outros atores. Assim, a experimentação de novas soluções não se dá somente com base em um questionamento neutro das próprias premissas, mas se dá em um ambiente permeado por valores que são constantemente contrapostos e que justificam as ações (BOLTANSKI; THÉVENOT, 1999).

Por meio de uma visão ecológica das estruturas, a teoria pragmatista situa a agência criativa. O contexto não é somente um limitador da ação, até porque não existe apenas um contexto que circunda o sujeito, mas diversos níveis de contextos, alguns mais imediatos, outros mais sistêmicos. Isso pressupõe uma explicação multinível, que requer também a existência de estruturas de intermediação entre esses níveis. Os atores situados nessas estruturas de intermediação teriam maior capacidade de ação criativa, visto que sua posição favorece a utilização dos diferentes recursos apontados. Isso significa que esses atores têm maior capacidade de identificar como se dá a distribuição e a diversidade dos elementos no tempo e no espaço para conectá-los e situá-los em processos já em curso (ANSELL, 2013).

A utilização da teoria pragmatista a partir de uma visão ecológica indica um processo em que, por um lado, dependendo das situações com as quais os atores se deparam, diferentes soluções são propostas; por outro, dependendo dos atores com os quais os sujeitos interagem e para os quais precisam justificar suas ações, argumentos diversos são acionados e ações distintas são propostas baseadas nos valores em disputa. Além disso, o contexto contribui para a explicação das ações, não sendo sempre um limite para a mudança, como nas descrições sobre dependência de trajetória. Existem multiescalas de contextos que afetam as ações de diferentes formas e uma evolução de contexto pode possibilitar uma ação que não seria possível em um momento anterior, não somente em função da trajetória passada, mas simplesmente porque o contexto não é estático.

Essa perspectiva difere da comumente utilizada nos estudos sobre burocracia e instituições políticas, mas não se desloca completamente dela. A teoria institucionalista, por exemplo, indica que a agência dos atores é mais perceptível em períodos de crise, que são vistos como janelas de oportunidades para empreendedores políticos emplacarem suas pautas (KINGDON, 2015). A própria literatura sobre empreendedorismo político ressalta o papel 
das instabilidades, mesmo as mais cotidianas, para que os atores possam agir de forma a modificar as instituições (SHEINGATE, 2003).

Por isso, diferencio os processos de evolução dos de ruptura. Evolução do contexto seriam as mudanças menos radicais que dizem respeito a um período curto (embora possam ser muito radicais se considerarmos um período longo), que possibilitam que as capacidades construídas ao longo do desenvolvimento da política encontrem respaldo no mundo externo ou sejam até mesmo impulsionadas por esse mundo externo. Nem sempre é possível indicar se é o desenvolvimento da política que motiva mudanças no contexto ou se são os desenvolvimentos dos atores que interagem com a política que geram mudanças na política, o que dá um sentido de coevolução da política e do ambiente que a cerca.

Ruptura, por outro lado, se refere às crises institucionais que modificam mais profundamente o ambiente que cerca a política. Nessas situações, os desafios postos aos atores podem mudar completamente, exigindo maior capacidade de encontrar soluções criativas. Para este capítulo, contudo, considero que os períodos de instabilidades são aqueles nos quais os atores se deparam com desafios mais complexos, e a crise, em si, não é suficiente para compreender seus desdobramentos. Isso porque, se a instabilidade favorece o empreendedorismo político, ela não indica quem o exercerá, ou seja, o empreendedor político pode ser tanto aquele que questiona as instituições quanto aquele que quer defendê-la. Os desafios são postos para todos de maneira diferente, mas nenhum deles tem uma resposta pronta para esses desafios. Depende, em grande parte, da capacidade dos atores de motivar a cooperação de outros para a sua solução proposta (FLIGSTEIN, 2001).

Para este texto, considero os burocratas da Senarc como ocupantes dessa posição de intermediação. Não são como burocratas de nível de rua que, embora tenham discricionariedade, não têm a competência para criar regras e procedimentos para além daqueles que estão permitidos ou orientados a organizar. São atores com autoridade para propor novos procedimentos e até regras que podem virar leis e normativas que vinculam toda a estrutura de implementação do Cadastro Único e PBF. Embora possuam alguma autoridade e as vantagens da intermediação, estão inseridos em um sistema que envolve diferentes atores, como órgãos de controle, políticos, entre outros. 
Também considero o conflito entre erro de exclusão e de inclusão apresentado na introdução como um conflito de valores que requer justificação de ambas as partes. Se utilizarmos a classificação dos critérios de justiça apontados por Boltanski e Thévenot (1999) podemos considerar que a defesa da prevenção do erro de inclusão tem a ver com uma lógica industrial que tem a eficiência como valor principal. Por outro lado, a defesa da prevenção do erro de exclusão se alinha mais a uma lógica cívica, que preza pela solidariedade e o interesse coletivo. É a partir dessa diferença entre critérios de justiça que se estabelece boa parte dos esforços de justificação que envolve as decisões tomadas pelos gestores do Cadastro Único e PBF.

Assim, a mudança ou manutenção de uma instituição ocorrerá em função da capacidade de os atores realizarem experimentos criativos que solucionem os problemas postos e darem sentido às suas ações para atores externos e para eles mesmos. Ocorrerá também a partir do momento em que se identifica que capacidades antes inexistentes passaram a existir, e que se pode aproveitar a oportunidade para realizar mudanças.

Essa pesquisa se difere de alguns dos estudos sobre o Cadastro Único e o Programa Bolsa Família que foram eficientes em mostrar os processos iniciais de formação dessas políticas mas analisaram pouco a atuação dos burocratas (ANDRADE; LIMA-SILVA, 2016). Ou mesmo de estudos que reforçam o papel do insulamento burocrático que possibilitou o desenvolvimento dessas políticas, mas se restringem a um período muito específico em que os conflitos não estavam tão presentes e o esforço dos atores para resolver os problemas decorrentes desses conflitos não era tão evidente (OLIVEIRA; LOTTA, 2015). Distancia-se, ainda, de estudos que buscam analisar o papel dos burocratas de nível de rua do PBF e Cadastro Único e suas percepções a respeito da política e de seus usuários (EIRÓ, 2015), pois essas pesquisas não são úteis para entender um conjunto de atores muito mais restrito e com bastante poder de decisão como são os burocratas de médio escalão.

\section{Experimentação criativa em diferentes contextos}

O marco teórico utilizado reforça o papel da criatividade para explicar a mudança institucional. Indica também que a criatividade não se dá isolada 
do contexto, e que o fato das situações terem múltiplas escalas e perspectivas é que dá aos atores elementos para agirem criativamente. Nesta seção são apresentados três contextos diferentes e os experimentos criativos possibilitados por cada um deles. Todos esses contextos são permeados por disputas de ideias sobre o que se deve priorizar, o erro de exclusão ou de inclusão, mas essa disputa acontece de diferentes formas. Embora a apresentação se dê a partir dos contextos escolhidos, não se considera que é o contexto que define que tipo de experimento pode ser realizado. O que se busca com esta seção é demonstrar como a evolução de uma política pública (na verdade, duas políticas imbricadas) interage com as evoluções e rupturas de contextos, modificando os tipos de experimentos criativos.

\subsection{Primeiro contexto: problemas a serem resolvidos e respaldo interno}

O primeiro contexto a ser apresentado é o de formulação do programa Bolsa Família e Cadastro Único. Logo no primeiro ano de execução do PBF, houve uma crise de confiança no programa devido a várias denúncias de fraudes e irregularidades (VIEIRA, 2011; LICIO, 2012). A Secretaria Nacional de Renda de Cidadania (Senarc), responsável pela gestão do programa, foi pressionada a qualificar os registros do Cadastro Único. Para isso foram definidas duas ações: a primeira consistiu em um série de averiguações cadastrais, que são cruzamentos da base de dados do Cadastro Único com outros registros administrativos que trazem informações de renda e composição familiar - como registro de trabalhadores inseridos no mercado de trabalho formal, de pessoas que recebem benefícios previdenciários e trabalhistas e de óbito - com o objetivo de verificar se a renda declarada no Cadastro Único é semelhante à renda inscrita nos outros registros; a segunda solução foi a criação de um pagamento aos municípios por registro feito no Cadastro Único que cumpriam todos os requisitos de qualidade da informação. Ao longo do tempo, esse pagamento por cadastro passou a fazer parte de um repasse financeiro feito aos municípios que remunera o desempenho aferido em atividades necessárias à gestão do Programa Bolsa Família, entre elas o cadastramento das famílias.

A primeira solução buscava resolver o principal problema do Bolsa Família: como viabilizar um programa que tinha a ambição de abarcar todas 
as famílias pobres e extremamente pobres do país. O próprio Programa Bolsa Família surge como um esforço de resolução do fracasso de um programa tido como mais completo para uma das servidoras, o Programa "Fome Zero". Para ela, não havia a possibilidade de parar para pensar no que fazer a partir desse fracasso. Como afirmou uma ex-gestora:

Tem que entender também a trajetória, a coisa do fome zero já tinha naufragado. E a coisa do fome zero era muito mais digamos próxima das realidades das pessoas, e era muito mais envolvente, envolvia as produções locais etc. Então essa solução Bolsa Família, transferência de renda era uma solução mais acachapante, vamos lá, nós temos que fazer acontecer, vamos registrar as pessoas e vamos pegar as suas declarações e vamos pra frente. (Entrevista realizada em 9 out. 2017).

Embora houvesse um problema a ser resolvido, não havia em nível federal nem em nível municipal uma estrutura responsável por executar esse registro conforme as experiências de outros países, ou seja, a partir de visitas domiciliares ou coletando informações suficientes das famílias que possibilitasse a utilização de means proxy, que são métodos de aferição da pobreza por meio de diferentes características da família, como despesas, patrimônio, escolaridade, para além do trabalho e renda. De acordo com uma ex-gestora, chegou-se a cogitar a contratação do IBGE para realizar o cadastramento das famílias, o que foi descartado a partir da decisão política de fortalecer os municípios.

A partir da necessidade de construção de regras simples para operacionalizar o programa em larga escala, surge o conceito de autodeclaração, que passa a ser fundante em toda a compreensão de quais dados podem ser utilizados para conceder benefícios do Bolsa Família e dar acesso a outros programas sociais. A autodeclaração significa que os dados registrados no Cadastro Único serão declarados por um responsável pela família, sem a necessidade de comprovação documental nem de checagem por um servidor público por meio de visitas domiciliares.

A renda declarada passou a ser principal informação utilizada para definir quem é habilitado a receber o benefício ou não. Ia na contramão de outros 
programas de transferência de renda latino-americanos, que utilizavam os means proxy. Por outro lado, não se diferenciava significativamente de outros registros, como a declaração para fins de imposto de renda, em que a pessoa declara a sua própria renda e só precisa comprovar o declarado caso seja identificada alguma inconsistência. Como afirma uma entrevistada:

Eu acho que a autodeclaração olhando a posteriori [...] é uma pegada do que é possível ser feito. [...] Essa a minha visão, óbvio, escuta: nós estamos no Brasil, num país de milhões e milhões de pessoas onde tem milhões e milhões de pobres morrendo de fome agora! [...] É uma coisa meio prática, assim. Precisamos agora dar dinheiro para as pessoas que estão morrendo de fome. [...] Depois a gente foi elaborando a posteriori, olha, por que não ser autodeclarado? Afinal, pra todo o resto é autodeclarado, você percebe que todo o resto é autodeclarado, a não ser os salários ganhos no setor privado, que é o empregador que declara pra você. Aí a gente foi sofisticando esse entendimento e delimitando bem esse conceito. (Entrevista realizada em 9 out. 2017).

O relato da entrevistada ilustra bem o processo de experimentação que gerou a ação criativa. No caso, os servidores da Senarc tinham um grande problema à sua frente, que era o de registrar milhões de famílias para cumprir a meta de incluí-las em um programa que tinha a ambição de erradicar a pobreza no Brasil. Para isso, construíram novos conceitos que passaram a estruturar todo o Cadastro Único e a forma como os beneficiários do PBF e de outros programas que posteriormente iriam utilizar o Cadastro Único seriam habilitados.

A solução da autodeclaração trouxe um problema: se a informação é declarada pela família, como garantir que as famílias não vão mentir a renda para conseguir se habilitar ao programa? É comum que registros autodeclarados tenham algum tipo de checagem de dados, a exemplo da malha fina da Receita Federal para a declaração de imposto de renda. Isso, aliado à precariedade com a qual a junção das bases de dados dos programas que deram origem ao PBF foi feita, trouxe grandes questionamentos a respeito da qualidade dos dados do Cadastro Único e a consequente focalização do PBF. De acordo com uma entrevistada: 
Você tem muita crítica ao Bolsa Família, muita na mídia. Era paulada de que não havia focalização, os benefícios eram justapostos, sobrepostos, então quando se pega o Cadastro, a que não se tinha acesso até então. Então o Cadastro chega no MDS no início de 2005, de fato você vê que era um cadastro que não permitia nem a atualização de registro. Então se tu tivesses que atualizar o teu, tu entravas duplicado. Então tinha muita família fora, família duplamente dentro. Então você precisava analisar minimamente aquilo ali. (Entrevista realizada em 31 out. 2017).

As ações de averiguação cadastrais surgiram em 2005 em decorrência dessas denúncias de famílias que recebiam o benefício do PBF indevidamente. O Tribunal de Contas da União (TCU) e a Controladoria Geral da União (CGU) tiveram um papel importante nesse período, visto que a averiguação surgiu também como resposta a recomendações feitas por estes órgãos (VIEIRA, 2011). Ao longo dos anos, as averiguações cadastrais foram tomando corpo e desenvolvendo procedimentos cada vez mais padronizados de encaminhamento. Contudo, esse processo não é linear, e será melhor explicado a partir da apresentação dos outros contextos.

Ao normatizar a estrutura implementadora do PBF e do Cadastro Único, decide-se por delegar aos municípios o cadastramento das famílias. Essa decisão se insere no bojo das ações de descentralização na implementação de políticas públicas que vem desde a constituinte. Teve como protagonista a secretária da Senarc, Rosani Cunha, escolhida por Patrus Ananias para solucionar a crise de legitimidade por ser uma gestora de carreira que conciliava conhecimento técnico e experiência com o movimento municipalista. ${ }^{1}$ Assim como a autodeclaração, definir como competência dos municípios a realização dos cadastros que dariam acesso a

1 O Movimento Municipalista luta por maior descentralização política pró-municípios e o equilíbrio federativo (BATISTA, 2008). 
benefícios sociais foi uma decisão que ia na contramão de políticas com perfil semelhante. ${ }^{2}$

Tanto a autodeclaração com checagem a posteriori (averiguação cadastral) quanto a delegação da competência de cadastramento aos municípios e a consequente viabilização dessa atribuição ${ }^{3}$ foram soluções altamente inovadoras, visto que se diferenciavam tanto de modelos internacionais que poderiam inspirar o Programa Bolsa Família e Cadastro Único quanto de práticas normalmente realizadas na administração pública e que buscavam resolver problemas complexos. Essas soluções foram possíveis pela urgência do problema a ser resolvido, mas principalmente pelo respaldo interno que os gestores tinham dentro do Ministério do Desenvolvimento Social. De acordo com uma entrevistada:

Naquela época a gente tinha muita liberdade para criar, tinha respaldo. Não era simples você vender uma ideia não, pro ministro. Mas uma vez que ele se convencesse que era por aí, não ficava querendo saber de detalhes de portaria. Ele confiava na Conjur dele, confiava na assessoria de controle interno, que eram de fato pessoas muito sérias, que teve um papel fundamental na estruturação do MDS, e confiava na gente, de que a gente ia colocar no papel aquilo que de fato estava mostrando no gabinete do ministro. (Entrevista realizada em 27 abr. 2017).

2 No Brasil, o principal órgão que provê um registro administrativo utilizado para dar acesso a benefícios sociais é o Instituto Nacional de Seguro Social (INSS). Nesse caso, a instituição é federal, descentralizada nos municípios. Todas as responsabilidades relacionadas ao registro, seleção e concessão de benefício é feita por servidores ligados ao governo federal.

3 Para viabilizar o cadastramento das famílias pelos municípios, o governo federal passou a remunerar os municípios por cadastro realizado dentro dos requisitos estipulados. Após algum tempo essa remuneração foi institucionalizada a partir o Índice de Gestão Descentralizada, que reúne indicadores de qualidade do cadastramento e do acompanhamento de condicionalidades do PBF e é utilizado para calcular um valor de repasse financeiro aos municípios (BICHIR, 2011). 
No início do PBF e do Cadastro Único, havia um vazio de regulamentação, e foram os próprios servidores que construiriam essa regulamentação. Muitas das principais características atuais dessas duas políticas não existiam; a construção dos instrumentos de gestão do PBF e do Cadastro Único foram possíveis por meio da experimentação.

Essa possibilidade de experimentação sem muitas amarras se deu, de acordo com Oliveira e Lotta (2015), devido à estratégia de insulamento burocrático da Senarc, que teve como principal característica a garantia de autonomia do corpo burocrático formada principalmente por atores com grandes conhecimentos em gestão pública. Diferentemente de outras políticas do próprio Ministério, a equipe da Senarc tomava as principais decisões referentes ao desenho do programa de forma autônoma, sem consultar atores interessados, como representações de estados e municípios ou da sociedade civil (LICIO, 2012). Mesmo que outros atores tenham sido envolvidos na gestão do Cadastro Único e Programa Bolsa Família, esse envolvimento se deu por meio da adesão e na operacionalização dos procedimentos decididos pelos técnicos da Senarc, e não no compartilhamento de decisões.

Não se pode negar, também, os valores da equipe que se formou em torno dessas duas políticas. De acordo com uma entrevistada:

Eu não consigo identificar na equipe alguém que tivesse uma preocupação com erro de inclusão maior do que o erro de exclusão. [...] não tem nada que se chegue próximo a um perfil conservador de política pública, entende? (Entrevista realizada em 31 out. 2017).

Assim, havia uma predisposição da equipe de gestores de encontrar soluções que minimizassem o erro de exclusão, e isso significava afrouxar as regras de inclusão, como a decisão pela autodeclaração. Outra equipe com tal grau de autonomia poderia ter chegado a soluções completamente diferentes se fosse norteada por outros valores. No caso em pauta, os atores foram possivelmente recrutados por compartilhar valores com a direção escolhida, visto que, de acordo com uma entrevistada: “Quando a Rosani Cunha, que era gestora, saiu da Casa Civil, ela trabalhava na Casa Civil, foi ser a titular da Senarc, ela trouxe um grupo de gestores muito grande. [...] Até então o MDS não tinha quadro” (Entrevista realizada em 5 mai. 2016). 
Ao mesmo tempo, enquanto existia um grupo de servidores com autonomia para tomar decisões que resolvessem os problemas enfrentados, havia uma Secretária que intermediava diferentes níveis: tinha interlocução com o ministro e com os municípios aos quais se delegava a implementação do registro das famílias. É possível considerar que somente o conhecimento técnico dos gestores não seria suficiente para desenvolver soluções tão inovadoras para os problemas enfrentados, até mesmo porque as possibilidades de emulação de outras experiências não levavam às soluções encontradas. Essas, por sua vez, foram possíveis porque a principal autoridade da secretaria era responsável pela interlocução com os municípios, ciente de que não havia estrutura para o registro das famílias utilizando os procedimentos definidos em outros países, mas com a confiança de que com algum apoio e flexibilidade nas regras de coleta dos dados eles poderiam ser protagonistas nessa tarefa.

Foi um contexto em que a equipe estava imersa em um ambiente conflituoso, contudo, uma das soluções dadas para esse conflito foi o próprio insulamento da equipe que geria o programa. Os problemas eram urgentes, e as soluções não eram óbvias, muito menos apolíticas, embora tenham uma justificativa tida como técnica para cada uma delas. Dar a possibilidade de a família autodeclarar a sua situação requer um valor ligado à facilitação das formas de acesso ao programa. Atribuir a responsabilidade de coleta de informações aos municípios facilitando o repasse de recursos para viabilizar essa coleta pressupõe uma confiança nas capacidades municipais. Esse afrouxamento dos controles sobre a família e sobre o município será questionado pelos órgãos de controle, e é nesse contexto que se inserem as próximas inovações.

\subsection{Segundo contexto: questionamento externo e respaldo interno}

Não se pode definir quando se inicia o segundo contexto, mas um marco foi elencado por alguns dos entrevistados: a primeira grande averiguação, em 2009, ocorrida por demanda do Tribunal de Contas da União (TCU), que expôs o Programa Bolsa Família como um programa que beneficiava famílias com posses caras, como carros. De acordo com uma entrevistada, naquele ano os resultados da averiguação foram muito impactantes: 
E o batimento com o Renavam (Registro Nacional de Veículo) foi muito chocante pra nós. Foi o primeiro feito. Porque expuseram o programa na mídia como um programa que tinha gente com 20 caminhões, que tinha um Ford Focus, tal. E a Lúcia era diretora do Cadastro, optou por ir a campo, amostralmente, e por fazer um aplicativo. [...] Quando se foi a campo no Renavam, obviamente em uma amostra não probabilística, a gente foi em poucos casos, o que se viu foi que uma família que tinha 20 caminhões, se ela tivesse, era melhor ela dormir num dos caminhões. Moravam num barraco. (Entrevista realizada em 31 out. 2017).

As soluções encontradas nesse contexto foram a argumentação e o levantamento de evidências para tal. Para isso, os gestores do Cadastro Único buscaram formas de demonstrar que o problema não estava no Cadastro Único, e sim nas outras bases de dados com as quais o cadastro estava sendo comparado. A visita a campo teve esse propósito e é vista por alguns dos gestores como um marco no entendimento de que a autodeclaração podia ser melhor do que as informações contidas em outros registros.

A atuação dos órgãos de controle, na verdade, acaba por ser uma constante em todo o processo da construção das averiguações cadastrais. Em algumas situações eles estavam correndo atrás da equipe da Senarc em desvantagem técnica, em outras eles publicizavam fatos que, por mais que não fossem conclusivos, fragilizavam a gestão do PBF e o Cadastro Único. O papel desses órgãos foi crescendo ao longo do tempo, na medida em que a própria equipe da Senarc conseguia antecipar algumas das demandas que poderiam ser feitas por eles. Ao longo das entrevistas, os órgãos de controle eram vistos como atores que forçavam a Senarc a responder sobre os erros de inclusão, acionando valores menos priorizados pelos gestores. Essa é uma dinâmica que se intensifica na medida em que os órgãos de controle vão adquirindo maior capacidade técnica e força política.

Internamente, na Senarc havia uma divisão de tarefas em que o departamento de Cadastro Único respondia os questionamentos do TCU e o departamento ligado às ações de fiscalização do programa respondia os questionamentos da Controladoria Geral da União (CGU). Enquanto o departamento do Cadastro Único adquiria cada vez mais habilidade para 
demonstrar a consistência dos processos de checagem de dados ao TCU, a CGU, que tinha uma visão mais punitivista, de acordo com uma servidora, foi adquirindo recursos e argumentos para questionar de forma cada vez mais incisiva os procedimentos adotados.

Nessa divisão de tarefas, o departamento responsável pela fiscalização não tinha todos os argumentos necessários para responder questões como: por que não é dado um tratamento mais duro para as famílias que sempre são identificadas em averiguações cadastrais? Essas questões só passaram a ser respondidas a partir da mobilização, por parte desse departamento, dos demais departamentos.

Concomitantemente, se no início do Programa Bolsa Família a prioridade era facilitar o acesso das famílias ao Cadastro Único, com o passar do tempo observou-se que em muitos municípios a estimativa de famílias pobres e extremamente pobres já estava incluída no Cadastro Único. Considerando que era essa a estimativa que subsidiava o cálculo do total de benefícios disponível aos municípios, isso significava que se as estimativas não fossem atualizadas, o programa não poderia mais crescer até não haver mais ninguém identificado como pobre. ${ }^{4}$ Foi nesse período que se começou a identificar uma "fila de espera" para participar do programa, visto que o total de benefícios estimados como suficientes para erradicar a pobreza e extrema pobreza já estavam sendo atingidos em diversos municípios.

Para os gestores do programa, isso trouxe uma lógica de que, para além do problema de focalização, manter uma pessoa fora dos critérios dentro do PBF seria tirar a oportunidade de outra pessoa de participar do programa. Assim, construiu-se a narrativa de que a boa focalização do programa seria necessária para incluir justamente as pessoas que mais precisavam. Logo, para contemplar os mais necessitados, fazia-se necessário excluir os menos pobres. Como afirma uma entrevistada:

4 Essa característica não é inerente a programas focalizados. O Benefício de Prestação Continuada, que concede um benefício para idosos e pessoas com deficiência inseridos em famílias de baixa renda, não tem um limite de benefícios. Por ser um direito previsto em lei, qualquer pessoa que cumpra os requisitos receberá o benefício, independentemente de a estimativa de famílias com o perfil já ter sido contemplada ou não. 
Então acho que a averiguação sempre viveu nessa dubiedade, uma que é a dubiedade, que você tem uma meta de 11 milhões de famílias, você tem que cuidar de incluir as pobres [...]. Então estar alguém que não devia era de fato não estar alguém que devia. Então ela tem a dubiedade da inclusão e da exclusão. (Entrevista realizada em 31 out. 2017).

Dessa forma, os questionamentos externos feitos pelos órgãos de controle e as avaliações internas dos próprios gestores sobre a focalização do programa motivou a construção de normativas e orientações cada vez mais padronizadas de encaminhamento. Em 2015, os gestores da Senarc sistematizaram os procedimentos utilizados na averiguação cadastral, conectando-os com outros procedimentos de qualificação dos dados do Cadastro Único, como a revisão dos registros desatualizados há mais de 24 meses e a exclusão lógica dos registros desatualizados há mais de 48 meses. Nesse momento foram definidos critérios de gravidade da inconsistência cadastral, como a reincidência em averiguações cadastrais, que deram margem para o tratamento diferenciado de famílias com inconsistências consideradas pelos gestores como mais graves. Nesse ano, o público chamado a atualizar o cadastro em decorrência da averiguação cadastral dobrou em relação ao maior público convocado nos anos anteriores.

A lógica da sistematização feita em 2015 foi repetida nos anos seguintes. Contudo, os critérios de gravidade das inconsistências e os encaminhamentos a serem dados para cada grupo foram atualizados a cada ano, visto que não havia uma normatização geral que indicasse quais tipos de inconsistência são mais graves do que outras, e sim decisões específicas a partir da análise dos resultados de cada ação de averiguação cadastral.

Essa normatização, contudo, não resolveu todos os questionamentos feitos pelos órgãos de controle. Se os procedimentos de averiguação se tornam mais sistemáticos e precisos, fica cada vez mais difícil diferenciar uma informação inconsistente em função da desatualização do cadastro da família de uma atitude de má fé da família no momento de prestar informações ao Cadastro Único. As distinções entre averiguação cadastral e 
fiscalização ${ }^{5}$ tornam-se cada vez mais esfumaçadas e os órgãos de controle passam a questionar não só a autodeclaração mas também a ausência de exigência de devolução do valor de benefícios recebidos indevidamente. Para uma servidora:

A CGU foi então aprendendo a fechar o cerco. [...] E ao questionarmos sobre essa situação da gente não poder tratar os achados de batimento dela, porque ali tinham famílias que não tinham atualizado cadastro após a obtenção da renda nova, ela passou a tirar isso também. Então ao final desse processo a CGU estava verificando a data de entrada no emprego formal, pela renda que ela achava de membro familiar, e a atualização cadastral, a última data de atualização cadastral e se essa atualização cadastral tinha acontecido depois da obtenção da renda. Então, ela começa agora no final a apresentar para a gente só esses achados. [...] Aí não tem jeito, se ela identifica uma renda nova, não lançada e essa renda foi obtida antes da última atualização cadastral, significa que a família omitiu essa renda. (Entrevista realizada em 14 dez. 2017).

Durante o fim de 2015 e início de 2016, ainda antes do impedimento da presidenta Dilma Rousseff, o Departamento do Cadastro Único encabeçou, na Senarc, a pauta da integração de bases de dados e sistemas de informação. Foi organizada uma oficina nacional com órgãos do governo federal, gestores de grandes bases de dados e sistemas de informação, como a Dataprev, a Receita Federal, o Ministério do Trabalho e Previdência Social, entre outros, e um seminário internacional para conhecer experiências de integração de bases de dados e sistemas de informação em outros países. ${ }^{6}$

5 De acordo com a Nota Técnica 113 Senarc/MDS de 12 de maio de 2016, a fiscalização do PBF consiste na apuração de recebimento indevido de benefícios em função de informação falsa prestada de forma intencional pelos beneficiários ou por agentes públicos, o que se diferencia da checagem em lote da consistência das informações dos registros das famílias por meio de cruzamentos de bases de dados.

6 As informações sobre o Seminário Internacional de Integração de Bases de Dados e Sistemas de Informação podem ser encontradas no seguinte link: http://wwp.org.br/eventos/ 
Entre os temas discutidos nesses dois eventos, os participantes destacaram o da cooperação entre diferentes órgãos governamentais para a integração de dados e uma visão de conhecimento da realidade dos cidadãos a partir de dados de diferentes fontes. Era uma pauta que parecia ter em mente tanto a provisão de serviços públicos considerada mais adequada para cada perfil de cidadão como a racionalização da utilização dos recursos públicos, visto que seriam aperfeiçoados os mecanismos de identificação de sobreposição de recursos destinados para um mesmo cidadão.

Ao discutir integração de bases de dados, os próprios gestores começam a reavaliar o conceito de autodeclaração. Eles passam a ter contato com experiências internacionais que já utilizaram a autodeclaração e a utilizar outros métodos de registro das informações das famílias. Além disso, buscam uma aproximação com outros órgãos com a finalidade de acessar bases de dados que poderiam ser integradas ao Cadastro Único. De acordo com uma ex-gestora:

Eu acho que era um procedimento meio natural para nós chegar nesse ponto, e chegar no ponto não só da averiguação. A gente só faz averiguação a posteriori porque a gente não tem condição de fazer na habilitação, a priori. (Entrevista realizada em 9 out. 2017).

Na verdade, a checagem de dados na habilitação já vinha sendo testada, mas em função de dificuldades técnicas ela não era possível. A autodeclaração, embora tenha sido uma justificativa importante tanto para os órgãos externos quanto para a construção da lógica de operação do Cadastro Único, parece ter sido sempre algo que poderia ser substituído caso fosse encontrada uma solução mais adequada. De acordo com uma ex-servidora:

Assinamos um contrato com a Dataprev, que não sei se está vigente, mas assinamos um contrato com a Dataprev e o primeiro batimento que eles se comprometeram a fazer, era um batimento com a base de famílias habilitadas, ou

seminario-internacional-de-integracao-de-base-de-dados-e-sistemas-de-informacao-paraaperfeicoamento-de-politicas-publicas/. Acesso em 27/06/2017. 
seja, nós estávamos falando de fazer batimento com a fila. [...] A gente já estava em uma situação muito boa pra iniciar. O problema é que a Dataprev, pelo que eu consegui acompanhar, a Dataprev não conseguiu fazer as entregas pra gente de maneira minimamente adequada. [...] Minha posição como gestora era simples, eu hoje estou massacrando uma equipe pra fazer batimentos de uma maneira extremamente desestruturada em que qualquer erro que ocorra pode resultar em responsabilização dessa equipe. (Entrevista realizada em 27 out. 2017).

Nesse contexto de questionamentos externos e respaldo interno, a experimentação criativa se deu a partir da busca por evidências de que as soluções encontradas eram adequadas, da normatização de procedimentos e da antecipação de possíveis questionamentos. Os problemas a serem resolvidos se tornaram cada vez mais repetitivos e desafiavam as decisões tomadas na urgência da resolução dos grandes problemas. Isso faz com que as soluções sejam também no sentido de institucionalizar procedimentos com a finalidade de responder, tanto interna quanto externamente, que uma ação rotineira é feita para evitar erros de focalização.

Ao mesmo tempo, percebe-se que enfatizar o erro de exclusão em detrimento do de inclusão não era suficiente no momento da interlocução com os órgãos de controle. Assim, busca-se antecipar soluções para problemas que podem surgir a partir da identificação das brechas nos argumentos dados aos órgãos externos. O contrato com a Dataprev para a realização de checagens no momento da habilitação no programa e a realização do seminário de integração de bases de dados foram claros esforços de antecipação de possíveis questionamentos. O primeiro tentou superar entraves técnicos da própria Senarc que impediam um esforço de checagem mais constante; o segundo tentou identificar soluções encontradas por outros países para os mesmos desafios de forma que o Cadastro Único não ficasse sempre dependente da autodeclaração e das checagens a posteriori sempre questionadas pelos órgãos de controle.

Nesse momento, contudo, essas experimentações tinham maior caráter de sondagem das possibilidades do que de implementação de soluções. Em uma visão de coevolução, é possível perceber que a equipe da Senarc 
ainda não tinha como contar com outros atores do sistema para solucionar os problemas que enfrentavam, respondendo aos órgãos de controle de forma a manter as preocupações com o erro de exclusão e justificar os erros de inclusão. Nessa perspectiva, é possível argumentar que as condições necessárias para a resolução desse problema só se apresentaram no contexto seguinte.

\subsection{Terceiro contexto: questionamento externo e interno}

No final de abril de 2016, o TCU publicou que uma auditoria realizada pelo órgão encontrou mais de 160 mil famílias com indícios de irregularidade. Essa notícia foi repercutida nos principais jornais do país. ${ }^{7}$ Em 17 de abril de 2016 a Câmara dos Deputados aprovou a abertura do processo de impedimento da presidenta Dilma Rousseff, afastando-a temporariamente do cargo. No final de maio de 2016, o Ministério Público Federal publicou que 1,4 milhões de beneficiários do PBF estavam com inconsistências, o que abarcava $\mathrm{R} \$ 2,5$ bilhões de recursos pagos. ${ }^{8}$

Em aproximadamente um mês, os servidores da Senarc se viram em uma situação de incerteza e de ameaça muito grande. Não sabiam se o governo seguinte daria a mesma importância às políticas sociais que o governo petista tinha dado ou se havia intenções de modificar o desenho do programa. Precisavam, ainda, de responder os questionamentos de que a gestão do PBF e o Cadastro Único permitiam o pagamento de benefícios a famílias com irregularidades.

Junto com o alto escalão, partiram do MDS os secretários nacionais de todas as secretarias, exceto o da Senarc, que era um gestor de carreira. Enquanto boa parte dos diretores no ministério pediu exoneração, na Senarc somente um diretor saiu. A tônica nesse momento, na Senarc, era resistir por dentro, tentar defender o programa para que ele não fosse descaracterizado.

7 http://www1.folha.uol.com.br/poder/2016/04/1765505-em-auditoria-no-bolsa-familiatcu-aponta-12-de-beneficiarios-indevidos.shtml. Acesso em 27/06/2017.

8 http://www1.folha.uol.com.br/poder/2016/05/1776564-ministerio-publico-veirregularidades-de-r-25-bilhoes-no-bolsa-familia.shtml; http://www.raioxbolsafamilia. mpf.mp.br/raioxbolsafamilia/diagnostico. Acesso em 27/06/2017. 
Havia a percepção de que poderiam ser capazes de argumentar contra a nova direção e convencê-la a manter o desenho do programa por meio de justificativas técnicas.

Envoltos no contexto de incerteza e de questionamento, a solução encontrada pelos gestores foi criar um Grupo de Trabalho Interinstitucional (GTI) que contou com a presença de técnicos da Senarc, do Ministério do Planejamento, da CGU, do TCU, da Caixa Econômica Federal, e do Instituto Nacional de Seguro Social (INSS). Essa foi uma demanda da própria direção do MDS que, a partir da divergência de dados do Ministério Público Federal, do TCU e CGU e da averiguação cadastral realizada pela própria Senarc, solicitou um número único de inconsistências cadastrais, calculado a partir de uma metodologia única de trabalho.

De acordo com uma entrevistada da Senarc participante desse grupo, o início das ações foi mais político, contou com a presença do secretário executivo, mas à medida que o grupo se desenvolveu as discussões tornaram-se mais técnicas, e os consensos foram sendo construídos. Algumas servidoras do Cadastro Único buscaram emplacar a pauta da integração de bases de dados já em andamento, mas houve a priorização da construção de procedimentos restritos ao PBF em detrimento de estratégias voltadas ao Cadastro Único.

Embora o foco tenha sido mais nas estratégias de aumento do controle dos procedimentos do $\mathrm{PBF}$, de acordo com uma servidora:

no período foi muito difícil, foram seis meses, com os órgãos, até você explicar o que a gente já fazia, quais possibilidades a gente tinha de melhoria, que não dava pra fazer tudo da noite pro dia, foi difícil. Mas passado isso, eu vejo isso como uma coisa muito positiva, os projetos que a gente tinha de melhoria do Cadastro Único ganharam força depois do GT. (Entrevista realizada no dia 23 jun. 2016).

Para ela, foi uma oportunidade, inclusive, de encaminhar pautas que não tinham tanta importância na Senarc, como a da integração das bases de dados. Com o GTI, a Senarc passou a ter acesso a bases de dados que não tinha anteriormente. O diálogo com outros órgãos foi positivo porque foi possível compartilhar com outros atores os desafios envolvidos no cruzamento de bases de dados e avançar na discussão sobre a integração dessas bases. 
De acordo com a servidora pública, a instabilidade política aliada ao questionamento das ações de controle do Cadastro Único e PBF foram importantes para que essa pauta, ainda incipiente na Senarc, ganhasse força. Para ela, sem o fortalecimento dessa pauta dentro da Senarc, seria provável que nem pautas encabeçadas pelos próprios servidores fossem encaminhadas porque não eram prioridades da gestão anterior. De acordo com a servidora:

[...] com essa possibilidade de integrar essas bases de dados no planejamento eu tenho a oportunidade de melhorar o próprio processo de cadastramento. Ao invés de ficar mandando a família voltar várias vezes no ano, [...] abre essa possibilidade que talvez eu tenha de trazer essas bases de dados, posso ir lá, fazer os cruzamentos e dar uma resposta para família na hora que ela está incluindo ou atualizando, que é o que a gente sempre quis. Essa perspectiva nossa não mudou do GTI pra cá, a gente sempre quis isso antes do GTI. A própria equipe já tinha amadurecido essa evolução do cadastro, a necessidade de fazer checagens com menos tempo, o GTI só externaliza aquilo que a gente já lia. (Entrevista realizada em 23 jun. 2017).

A centralidade que a averiguação cadastral tomou com a mudança de governo possibilitou que pautas antigas fossem implementadas, como a verificação a priori das informações de renda para impedir a habilitação das famílias com dados inconsistentes. Se antes essa ação não era feita porque 0 cruzamento de dados que deveria ser automatizado ficava nas mãos de servidores que poderiam cometer erros e ser responsabilizados pela concessão ou cancelamento de benefícios, após o GTI, foram automatizados muitos dos batimentos, que passaram a ser implementados pela Caixa Econômica Federal ou pela Dataprev, que tinham mais recursos tecnológicos para isso.

Além disso, para além do processo anual de averiguação cadastral que mobilizava as gestões municipais, passaram a ser feitas também verificações adicionais das famílias já beneficiárias e das habilitadas que ainda não participavam do programa, ou seja, da fila de espera do PBF. Essas últimas passariam a ser impedidas de receber o benefício, mesmo tendo o perfil para isso, caso fossem encontradas divergências de informações. A viabilização de cruzamentos de bases de dados ocorreu de tal forma que uma família 
incluída nos processos de verificação da folha de pagamento do PBF e da lista de habilitados somente poderia acessar o benefício caso atualizasse 0 cadastro e declarasse uma renda semelhante à que estava contida no registro administrativo que apontara inconsistência de informações de renda.

Essa nova ação questiona o conceito de autodeclaração do Cadastro Único. Afinal, se a família deve declarar renda semelhante à renda do outro registro administrativo, a renda do outro registro é que está sendo utilizada como referência. Também questiona o conceito de autodeclaração o projeto encaminhado à Caixa Econômica Federal de averiguação online, que prevê a apresentação da renda de outros registros para o entrevistador do Cadastro Único no momento da inclusão ou atualização cadastral. Ora, se o entrevistador tem a informação de que uma pessoa tem uma renda específica, seria muito arriscado registrar outra renda, mesmo que a família assim declare. Dessa forma, o próprio desenvolvimento das ações mobilizadas pela equipe da Senarc e respaldadas por uma gestão que deu força às ações de averiguação questiona o conceito que deu base para a criação desses procedimentos.

Não é só em função do aumento da capacidade de cruzamentos de bases de dados que a autodeclaração passa a ser reavaliada. Enquanto alguns gestores veem com resistência o questionamento desse conceito que foi fundante para a operacionalização do Cadastro Único, outros acham que ele tem atrapalhado mais do que ajudado considerando os procedimentos que passaram a ser adotados após o GTI.

A primeira vez que eu me peguei defendendo a não declaração, a não autodeclaração do cadastro foi nesse novo governo [...]. Com todo esse negócio de pente-fino [...] uma das premissas é [...] que eu acredito mais na base de dados do que na declaração da família. Para mim, isso era claro, a base está aqui, está falando que não tem essa renda, vou acreditar na base e não vou acreditar na pessoa. [...] Só que o discurso era: "Não! Vamos manter a autodeclaração!" Só que se a família não declarasse aquilo que estava na base de dado, eu cortava o benefício dela, não ia adiantar nada e eu ia impedir ela vir pro Bolsa. Aí foi a primeira vez que eu falei "gente, se o Estado tem essa informação, se o Estado está falando que essa informação para ele é a mais crível e que para mim o que a família falar, eu não 
vou considerar, o que me importa é o que está na base de dados, então vamos usar a informação". [...] Então o Estado tem que se responsabilizar por estar tomando essa decisão, de que eu confio mais na base de dados. Não jogar o ônus para a família, não falar que ela mentiu. Não falar que o município que não dá conta. Vamos assumir que eu acredito na base de dados e vamos usar essa informação para concessão de qualquer benefício. (Entrevista realizada em 20 nov. 2017).

Essa fala mostra alguns dos desafios que os gestores do Cadastro Único e do PBF passaram a enfrentar quando os cruzamentos de bases de dados tornaram-se viáveis. Se a autodeclaração responsabiliza a família que deve informar sua situação, o cruzamento de bases de dados responsabiliza o Estado, que é detentor de diferentes registros coletados com metodologias distintas e precisa conciliá-las no momento de utilizar os dados para concessão ou cancelamento de benefícios. Se a forma de corrigir uma inconsistência identificada por meio de uma checagem a posteriori seria a convocação da família para uma atualização cadastral, com a checagem a priori, a família não tem como corrigir a situação a não ser informando o mesmo dado encontrado no outro registro ou corrigindo a informação que foi utilizada como referência na outra base de dados. Se o dado atualizado é visto como fidedigno, as gestões municipais precisam dar conta de simplesmente manter os dados das famílias atualizados, agora se é fidedigno o dado sem divergência com relação a outras bases de dados, não há o que as gestões municipais possam fazer para garantir a qualidade do dado, visto que elas não têm acesso às informações utilizadas nos cruzamentos de bases de dados.

Assim, no terceiro contexto, a experimentação criativa caracteriza-se por ser um aproveitamento de oportunidades viabilizado por meio de uma situação de coevolução. Se em um momento anterior os entraves apresentados por outros atores do sistema eram suficientes para protelar ações mais contundentes no sentido de prevenir o erro de inclusão, priorizando o erro de exclusão, neste momento, o contexto político forçou que esses entraves fossem superados. Com o questionamento externo e interno, as prioridades se modificaram e o que era dificuldade em um período anterior pôde se tornar viável. Contudo, a realização de projetos antigos de forma tão abrupta expôs muitas das contradições 
acomodadas ao longo da execução da política pública. Conceitos que antes foram válidos para operacionalizar o programa e o Cadastro Único passaram a ser reavaliados pelos próprios gestores que os forjaram.

O terceiro contexto ainda está em curso e não é possível saber quais serão os encaminhamentos para os desafios elencados. Contudo, a análise já mostra uma dinâmica bastante complexa de idas e vindas de decisões tomadas a respeito de como o Cadastro Único e o Programa Bolsa Família devem ser operacionalizados, dinâmica que se intensificou no contexto de ruptura política. Contudo, essas idas e vindas não são muito coerentes: situações que antes eram almejadas, mas avançavam com dificuldades, adquirem novo ritmo e se aproximam muito mais dos desejos dos burocratas. Contudo, isso vem acompanhado de um viés punitivista que contraria as crenças dos gestores, que resistem a algumas das mudanças, mesmo que elas não contradigam a própria trajetória da construção dessas políticas e se dispunham a outras, com o intuito de preservar essas mesmas crenças.

\section{Conclusão}

Este trabalho buscou responder à seguinte questão: a experimentação criativa ocorre da mesma forma em todos os contextos? Para isso, foram apresentados três contextos ao longo de duas políticas imbricadas, o Cadastro Único e o Programa Bolsa Família, e discutido como a experimentação criativa se deu nesses três contextos, que tinham em comum a disputa sobre se era mais importante priorizar o erro de inclusão ou de exclusão.

O conceito de autodeclaração ilustra bem esse processo: forjado pragmaticamente para possibilitar uma meta ousada e urgente, ele passou a ser considerado fundante para o Cadastro Único. Alcançada a meta e viabilizados meios de checagem das informações declaradas a priori, esse conceito perde a relevância. Contudo, ainda não se sabe qual o encaminhamento a ser dado para essa questão, porque este conceito estrutura a forma como é feita a coleta de informações em todos os municípios brasileiros. Há um impasse e é a partir desse impasse que se espera que surjam novas soluções, ainda imprevisíveis.

No primeiro contexto, o que se pôde perceber foi o papel de uma atriz situada entre diferentes níveis, dialogando com a equipe técnica e lhe 
auferindo autonomia para agir e resolver os problemas apresentados com os políticos e com os municípios, que seriam os atores implementadores da política. As inovações realizadas podem ser explicadas por essa capacidade de interlocução com os diferentes atores. Além disso, a secretária à época teve a possibilidade de criar uma equipe com homogeneidade de valores capaz de responder às necessidades postas de forma a fugir das práticas já existentes, mas não foram consideradas viáveis quando confrontadas com as dimensões dos problemas postos.

No segundo contexto, o que se identifica é uma situação de antecipação de problemas, construção de rotinas e justificação. É um contexto que favorece ações menos inovadoras, visto que as decisões tomadas partem mais de respostas aos outros atores do sistema do que à resolução de um problema propriamente dito. Isso porque, embora diferentes atores questionassem as decisões tomadas, não era prioridade forçar os outros atores do sistema a cooperar na busca de soluções que pudessem resolver os problemas postos. A defesa do erro de exclusão ainda era mais importante, e o erro de inclusão, para a equipe, era um problema que apenas começava a questionar as crenças dos servidores. Ainda assim, foi nesse contexto que as soluções para esses questionamentos internos e externos passaram a ser pensadas.

No terceiro contexto, a partir dos questionamentos internos e externos houve uma capacidade de maior inovação pela equipe da Senarc, ainda que parte dessa inovação contrarie as crenças dos servidores. Os outros atores do sistema foram pressionados a cooperar no momento de viabilizar ações que antes eram apenas planejadas. Nesse caso, pôde-se identificar uma situação de coevolução, mas essa situação não foi natural, mas pressionada a ocorrer. Se no período anterior a Caixa ou a Dataprev apresentavam empecilhos para realizar cruzamentos de bases de dados, no momento seguinte esses empecilhos foram forçados a serem superados.

A simples existência de uma crise política não explicou as mudanças e continuidades ocorridas após a ruptura institucional. A capacidade dos atores de negociar e experimentar soluções já em discussão para os problemas postos foi fundamental para que a política tomasse o rumo que tomou. Esse trabalho mostrou que, diferentemente das visões institucionalistas mais tradicionais, os atores foram capazes de reavaliar suas decisões, aproveitar oportunidades mesmo quando foram constrangidos e encontrar soluções 
inovadoras para os problemas que precisavam enfrentar. A crise política se assemelhou mais a um catalizador de ações, visto que, a partir dos problemas com que se deparavam, os gestores tiveram que avançar em temas ainda incipientes e pouco discutidos.

É evidente que o contexto importa, e este trabalho se soma a outros na tentativa de identificar como isso ocorre. Mas, a contrapelo de visões institucionalistas mais comuns, o argumento não é que contexto importa porque constrange os atores, visto que em todos os contextos apresentados os atores estão sendo constantemente questionados. O contexto importa porque apresenta novos problemas, exige esforços de justificação, inverte prioridades e força a implementação de soluções antes inviáveis. É uma visão que enfoca o papel do contexto na explicação de motivações para agir de uma forma e não de outra, e não no constrangimento dos atores que deixam de fazer algo em função de uma série de entraves.

\section{Referências}

ANDRADE, Fabio; LIMA-SILVA, Fernanda. High-level federal bureaucracy and policy formulation: the case of the Bolsa Família program. Brazilian Political Science Review, São Paulo, v. 10, n. 3, p. 1-26, 2016. ANSELL, Chris. Ecological explanation. In: BERK, Gerald; GALVAN, Dennis C.; HATTAM, Victoria (org.). Political creativity: reconfiguring order and change. Philadelphia: University of Philadelphia Press, 2013.

BATISTA, Matias. Os municípios nos governos FHC e Lula: uma abordagem sob o ponto de vista da ação legislativa. 2008. 58 f., il. Monografia (Especialização em Ciência Política) - Universidade do Legislativo Brasileiro, Brasília, 2008.

BERK, Gerald; GALVAN, Dennis. How people experience and change institutions: a field guide to creative syncretism. Theory and Society, v. 38, n. 6, p. 543-580, 2009. 
BICHIR, Renata. Mecanismos federais de coordenação de políticas sociais e capacidades institucionais locais: o caso do Programa Bolsa Família. 2011. 271 f., il. Tese (Doutorado em Sociologia e Ciência Política) - Instituto de Estudos Sociais e Políticos, Universidade do Estado do Rio de Janeiro, Rio de Janeiro, 2011.

BLUMER, Herbert. Symbolic interactionism: perspective and method. Englewood Cliffs, NJ: Prentice-Hall, 1969.

BOLTANSKI, Luc; THÉVENOT, Laurent. The sociology of critical capacity. European Journal of Social Theory, v. 2, n. 3, p. 359-377, 1999.

BRASIL. Ministério do Desenvolvimento Social. Nota Técnica $n^{0} 113$, de 12 de maio de 2016. Brasília: Senarc/MDS, 2016.

EIRÓ, Flávio. Pauvreté, stigmatisation et citoyenneté: le rôle des assistantes sociales dans le clientélisme brésilien. Comunicação. In: CONGRÈS DE L'ASSOCIATION FRANÇAISE DE SOCIOLOGIE, 7., 3 a 6 jul., Université de Picardie Jules Verne, Amiens, 2015.

FLIGSTEIN, Neil. Social skill and the theory of fields. Sociological Theory, v. 19, n. 2, p. 105-125, 2001.

JOAS, Hans. The creativity of action. Chicago: University of Chicago Press, 1996.

KINGDON, John W. The policy primeval soup. In: KINGDON, John W. Agendas, alternatives, and public policies. Edinburgh: Pearson Education, 2015.

LICIO, Elaine. Para além da recentralização: os caminhos da coordenação federativa do programa Bolsa Família. 2012. xv, 351 f., il. Tese (Doutorado em Política Social) - Instituto de Ciências Humanas, Universidade de Brasília, Brasília, 2012.

OLIVEIRA, Vanessa; LOTTA, Gabriela S. Implementando uma inovação: a burocracia de médio escalão do Programa Bolsa Família. In: LOTTA, Gabriela S.; CAVALCANTE, Pedro (org.). Burocracia de médio escalão: perfil, trajetória e atuação. Brasília: Enap, 2015. 
SEWELL JR, William H. A theory of structure: duality, agency, and transformation. American Journal of Sociology, v. 98, n. 1, p. 1-29, 1992.

SHEINGATE, Adam D. Political entrepreneurship, institutional change, and American political development. Studies in American Political Development, v. 17, n. 2, p. 185-203, 2003.

VIEIRA, Ana. A multiestratégia de implementação do Programa Bolsa Família e do Cadastro Único no período 2005 a 2007. 199 f., il. Dissertação (Mestrado Profissional em Saúde Pública) - Fundação Oswaldo Cruz Escola Nacional de Saúde Pública Sergio Arouca, Rio de Janeiro, 2011.

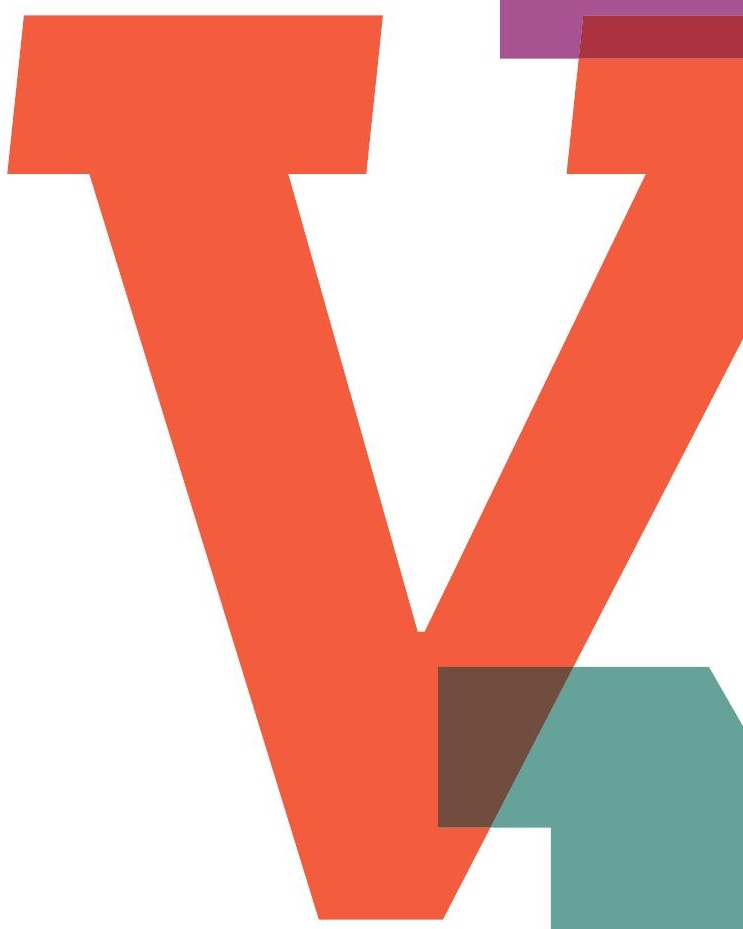

